\title{
Projetar o ambiente construído com base em princípios ergonômicos
}

\author{
Designing the built environment based on ergonomics \\ principles
}

\begin{abstract}
Thaisa Sampaio Sarmento Vilma Villarouco

Resumo

$\mathbf{O}$

s estudos de ergonomia visam adequar os ambientes às atividades desenvolvidas e aos anseios dos usuários. Historicamente, os estudos da ergonomia aplicada ao ambiente construído registram o foco direcionado às análises de situações existentes. Entretanto, recentes pesquisas vêm incorporando princípios de ergonomia no fazer projetual, como estratégia de antecipação de problemas, e permitindo a participação dos usuários nos processos decisórios. Este artigo aborda o processo de sistematização de etapas projetuais do ambiente construído, baseado em princípios ergonômicos. O objetivo é demonstrar como métodos de projeto podem ser enriquecidos, a fim de inserir os usuários finais em etapas projetuais, atendendo-os em suas necessidades e anseios. A metodologia utilizada é baseada em design science research (DRESCH; LACERDA; ANTUNES JUNIOR, 2015) e em duas abordagens ergonômicas: a metodologia ergonômica para o ambiente construído (VILLAROUCO, 2009, 2011) e as etapas de projetação ergonômicas de Attaianese e Duca (2012). São apresentadas abordagens teóricas e projetuais, parâmetros projetuais de ergonomia aplicados ao ambiente construído. Os resultados apontaram para uma forma de pensar o projeto baseado na compreensão de problemas pré-existentes, na participação ativa dos usuários e na adequação dos ambientes às atividades que nele serão desenvolvidas.

Palavras-chave: Ergonomia. Ambiente construído. Design science research. Projetoarquitetônico.

Abstract

Ergonomics studies applied to the built environment areaimed at adapting environments to the activities performed in them and to the desires of users. Traditionally, ergonomics analyses pre-existing situations. However, recent studies havebeenincorporating principles of ergonomics in design processes, as a strategy to anticipate solutions to problems and to include users in decisionmaking processes. This article discusses the systematisation of the built environment design process including ergonomics principles. The aim is to demonstrate how conventional design methods can be enhanced in order to include users' opinions and needs in the design stages. The research method is

${ }^{1}$ Thaisa Sampaio Sarmento ${ }^{1}$ Universidade Federal de Alagoas Maceió -AL - Brasil

${ }^{2}$ Vilma Villarouco ${ }^{2}$ Universidade Federal de Pernambuco Recife -PE - Brasil

Recebido em 05/12/19 based on Design Science Research (DRESCH; LACERDA; ANTUNES JUNIOR, 2015) and on two ergonomic analysis approaches: Ergonomic Methodology for the Built Environment (VILLAROUCO, 2009, 2011) and on the ergonomic design stages of Attaianese and Duca (2012). This paper presents theoretical and practical approaches and ergonomics parameters for the built design. The results point to a way of design thinking that is based on understanding pre-existing problems of similar environments, on the active participation of usersin the design process and on tailoring the built environment to human activities.
\end{abstract} Aceito em 05/03/20
Keywords: Ergonomics. Built environment. Design science research. Architectural design. 


\section{Introdução}

A ergonomia busca compreender a dimensão humana e suas características, para que a projetação de edificações ou de ambientes esteja adaptada ao indivíduo e, como consequência, os métodos ergonômicos se aproximem do usuário, quando da avaliação de suas satisfações e insatisfações, em busca de respostas para os problemas do processo projetual (FALCÃO; SOARES, 2011).

Mais que uma adequação técnica, ao se falar de projeto ativa-se um modo de pensar sobre um uso futuro, portanto a ergonomia aplicada ao projeto busca antecipar respostas aos problemas que, frequentemente, não são percebidos durante o processo projetual. Tais falhas e problemas despercebidos podem ter origens diversas, com especial atenção à pouca aproximação dos projetistas com os usuários finais, e até mesmo a uma idealização do futuro usuário, enquanto indivíduo médio ou padronizado.

Além de uma preocupação humana e inclusiva, pesquisas em ergonomia também tangenciam as questões de conforto ambiental e de usabilidade das edificações e dos ambientes urbanos, sem desmerecer o fator humano ao propor intervenções em espaços existentes, e até mesmo em projetos de novos ambientes.

Essencialmente, o propósito de uma edificação é abrigar seus usuários enquanto eles estão realizando suas atividades, sejam cotidianas, de trabalho, de lazer, de descanso, e vivendo suas vidas, nos diferentes locais de moradia e de convívio social. Sendo os edifícios meios de abrigo (BLAKSTAD; HANSEN; KNUDSEN, 2008), por sua vez produzem lugares para a realização das atividades humanas. Pink (2012) propõe uma definição de lugar para além das questões físicas, por meio da compreensão de como diferentes processos e coisas combinam-se para constituir o mundo experienciado pelas pessoas. Assim, um lugar assume uma concepção abstrata, em constante modificação, dependendo das interações humanas entre si, e entre as pessoas, os lugares e os objetos, ao realizarem-se atividades.

Pink (2012) discute os entendimentos das realidades empíricas de ambientes experimentados reais e as práticas que fazem parte deles, como parte de uma abordagem etnográfica do design de ambientes, e elabora alguns pressupostos, dos quais compartilhamos:

(a) a percepção humana é o centro da compreensão de lugar;

(b) os espaços podem ser eventos temporais, não sendo apenas delimitações físicas, envolvendo o tempo e os contextos social e cultural; e

(c) as pessoas são organismos que fazem parte do ambiente em que vivem e trabalham, incluindo as diversas formas de contextualização.

Canter (1985) e Bonnes e Secchiaroli (1995) também estudaram o conceito de lugar e elaboraram um significado cognitivo e afetivo deste, definido com uma "unidade de experiência ambiental" (CANTER, 1985; BONNES; SECCHIAROLI, 1995). Os lugares estariam definidos sob três fatores aglutinadores: "[...] atividades acompanhadas de atributos físicos (forma), aos quais incorporam concepções [...]" (CANTER, 1977), resultando em um diagrama que ressalta as relações entre os três componentes - forma, atividade e concepção (Figura 1). Essa teoria foi bastante utilizada para estudos sobre o comportamento dos usuários em espaços urbanos, especialmente no fim do século XX.

O diagrama ressalta as relações indissolúveis entre os elementos que compõem o lugar, levando em consideração a relação entre a forma e o conceito dos lugares e os usuários. Castello (2006) complementa que a definição de lugar envolve a percepção de suas potencialidades para a realização de experiências, ou seja, o lugar tem um significado simbólico para seus usuários (CASTELLO, 2005; MALARD, 2006; MERLEAU-PONTY, 1971).

Figura 1 - Diagrama de Canter

Fonte: Canter (1977, p. 158).

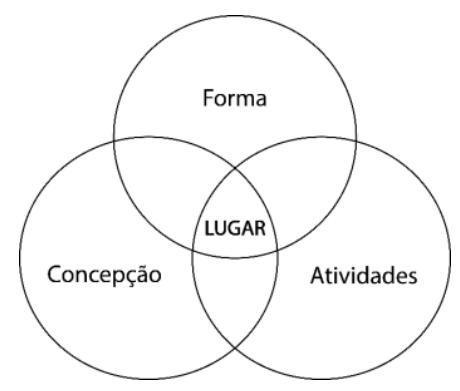

122 Sarmento, T. S.; Villarouco, V. 
Dependendo de quão bem as edificações forem projetadas para apoiar as atividades de seus usuários, os ambientes internos podem contribuir para a eficiência, a eficácia e a satisfação dos usuários. Isso é o que se chama de usabilidade dos edifícios (BLAKSTAD; HANSEN; KNUDSEN, 2008). A usabilidade das edificações está diretamente ligada à ergonomia do ambiente construído, tanto acerca dos aspectos físicos, quanto sobre o contexto de como esse ambiente é utilizado, envolvendo as experiências do uso e relacionando-se com a abordagem de Pink (2012) quanto à percepção humana sobre o lugar vivenciado.

Este artigo discute as etapas inerentes ao fazer projetual para projetar o ambiente construído, considerando experiências vivenciadas pelos usuários em lugares semelhantes, ou ao realizar atividades análogas. São detalhadas as formas de enriquecer o processo projetual com requisitos ergonômicos, que impactam tanto nos papéis definidos para os agentes envolvidos, como nas técnicas e nos instrumentos de projetação. O objetivo do artigo é sistematizar um processo de projeto para o ambiente construído, baseado em princípios ergonômicos. Sugere-se um aprofundamento teórico em fases iniciais do projeto, com base em análises ergonômicas prévias (de ambientes existentes similares) para proporcionar aos projetistas anteverem equívocos projetuais, antes da execução final de suas ideias.

O campo de experimentação que subsidia este artigo é composto por experiências de ensino e pesquisa realizados em disciplinas de graduação e pós-graduação, de ergonomia e de projeto desenvolvidas pelas autoras na Faculdade de Arquitetura e Urbanismo das Universidades Federais de Alagoas e de Pernambuco, no Programas de Pós-Graduação em Design e no de Ergonomia da Universidade Federal de Pernambuco e no Programa de Pós-Graduação em Arquitetura, Urbanismo e Design da Universidade Federal do Ceará.

\section{Referencial teórico}

O referencial teórico aborda o processo projetual, em uma abordagem histórica e enquanto fazer projetual, os contextos da projetação ergonômica, e o projetar para o espaço de atividade e com a participação dos usuários.

\section{Processo projetual}

De acordo com uma breve abordagem histórica, a profissionalização do papel do arquiteto começou na Inglaterra, no final do século XIX, com a criação de clubes e associações com o intuito de exercer um controle, uma valorização dos profissionais existentes e a elevação dos padrões profissionais do construtor que elaborava projetos. Entretanto, criou-se um distanciamento, cada vez maior, entre o trabalho de projetar e o de executar as obras. Ao longo do século XX, a tarefa de intervir no ambiente construído tornou-se cada vez mais complexa, sendo enriquecida por normas, regras, detalhes e parâmetros projetuais, especialmente na Europa e nos EUA. Lawson (2011) relata a evolução do pensamento do projetista ao longo da história e esclarece que a atividade profissional de projetar tornou-se mais exigente com o advento da industrialização, e destaca que a separação entre o projetar e o fazer também resultou na valorização do desenho (o projeto em si), já que este reúne as instruções e as transmite aos executores por meio da linguagem gráfica, dispensando a presença do projetista em tempo integral na oficina, na fábrica ou no local da obra. Essa medida permitia ao projetista desenvolver mais projetos de uma só vez, já que se dispensava fazer o acompanhamento diário da execução.

Hoje, vê-se maior distanciamento entre o projetista e o usuário, especialmente quando se trata de um projeto para uso público, ou coletivo, no qual arquitetos comumente adotam manuais técnicos de dimensionamento de ambientes, como forma de elaborar briefings resumidos e programas arquitetônicos reduzidos a lista de ambientes com uma área construída e consideram os futuros usuários indivíduos padronizados. Os diversos manuais de projeto que surgiram no período modernista foram frutos das ideias racionalistas, que tentaram reduzir o ser humano a um padrão dimensional e estético a ser reproduzido, sem uma reflexão sobre as implicações do espaço físico no comportamento humano e vice-versa.

Enquanto fazer profissional, pode-se compreender o processo de projetar de diversas maneiras. A primeira delas ocorre por meio do detalhamento das etapas projetuais, como visto em Voordt e Wegen (2013), em Sander (2000), em Anderson (2011) e em Kowaltoskiet al. (2006). Outra maneira é pela compreensão dos agentes principais que conduzem o fazer projetual, e das habilidades necessárias, como visto em Guardavilla (2016), Lawson (2011) e Anderson (2011). Uma terceira maneira de abordar o processo projetualé estudar os métodos, as técnicas e as ferramentas projetuais, com ênfase no atendimento das necessidades dos usuários, como visto em Villarouco (2011), Attaianese e Duca (2012) e Pazmino (2015).

Voordt e Wegen (2013) identificaram cinco fases: 
(a) fase exploratória (desenvolvimento de primeiras ideias);

(b) elaboração do programa de necessidades;

(c) estudo do projeto inicial;

(d) especificações e escolha da empreiteira; e

(e) uso e gerenciamento da edificação.

Guardavilla (2016) definiu os papeis desempenhados pelos principais agentes que interferem na projetação (Quadro 1).

Destaca-se a função do projeto, como materialização do ato de pensar sobre o ambiente a ser construído, como centralidade processual e o resultado material do saber profissional do arquiteto. Anderson (2011) definiu a atuação em projetos de arquitetura, ou de ambientes, enquanto habilidades a serem desenvolvidas pelos projetistas: resolver questões complexas; pensar em soluções múltiplas, realizar julgamentos críticos sobre suas propostas; fazer - refletir sobre o projeto e trabalhar com restrições projetuais. Guardavilla (2016) explica os componentes essenciais do trabalho do projetista, que envolve dominar algumas competências (Quadro 2).

Pazmino (2015) estudou técnicas e ferramentas de projeto em design e inicia seu livro com uma abordagem sobre criatividade em projeto de artefatos, objetos e sistemas. Ao longo do século XX, acreditava-se que o projeto seria um processo misterioso, denominado black box, ou caixa preta, cheio de partes obscuras e não descritível, fruto da experiência e do repertório do projetista, como alguém de puro talento criativo. Essa visão foi vencida quando Jones (1978) estabeleceu estudos baseados em glass box, ou caixa transparente, permitindo explicar o processo de projeto por meio de técnicas totalmente compreensíveis, como ilustrado em Sarmento e Gomes (Figura 2).

Na década de 1960 os estudos sobre método de projeto estavam baseados na intenção de resolver problemas por meio de uma abordagem sistemática e eficiente (VOORDT; WEGEN, 2013), com estudos dos processos projetuais de maneira tecnicista feitos por Jones e Thornley (1963), Alexander (1971) e Luckman (1967) a partir de decomposição de tarefas, resolvendo os problemas separadamente. Na década de 1970 as pesquisas começaram a abordar questões sociais dos ambientes edificados, por meio do estudo dos moradores dos locais e do gerenciamento dos projetos, com contribuições de DeJonge (1960), Sommer (1969), e Canter e Craik (1981). Na década de 1980, Alexander (1971) destacou-se com seus estudos projetuais baseados em padrões e sobre o ciclo projetual análise-síntese-avaliação (VOORDT; WEGEN, 2013). Sanoff (2001) desenvolveu ferramentas para inserção da percepção e dos desejos dos usuários em intervenções projetuais.

\section{Quadro 1 - Agentes envolvidos no projeto e suas funções}

\begin{tabular}{|c|c|c|c|}
\hline Projetista & Contratante & Usuário & Construtor \\
\hline $\begin{array}{l}\text { Sujeito que opera/articula } \\
\text { o sistema da edificação - } \\
\text { enquanto sistema } \\
\text { produtivo destinado a } \\
\text { abrigar as atividades } \\
\text { humanas }\end{array}$ & $\begin{array}{l}\text { Sujeito que promove } \\
\text { a execução da } \\
\text { edificação, primeiro } \\
\text { proprietário, que } \\
\text { pode ser público ou } \\
\text { privado }\end{array}$ & $\begin{array}{l}\text { Sujeito aquele a quem } \\
\text { é destinado o uso do } \\
\text { artefato edificado. Pode } \\
\text { coincidir com o } \\
\text { contratante em } \\
\text { edificações privativas }\end{array}$ & $\begin{array}{l}\text { Sujeito que realiza a } \\
\text { obra edificada, } \\
\text { entregando o edifício } \\
\text { ao contratante ou aos } \\
\text { usuários }\end{array}$ \\
\hline
\end{tabular}

Fonte: baseado em Guardavilla (2016).

\section{Quadro 2 - Competências que o projetista deve desenvolver}

\begin{tabular}{|l|l|}
\hline O método projetual & Organização lógica e sequencial do trabalho projetual. \\
\hline O conhecimento técnico & $\begin{array}{l}\text { Domínio da história, das técnicas construtivas, das tipologias e } \\
\text { materiais, das normas técnicas, das formas de representação, da } \\
\text { ergonomia, do conforto ambiental, etc. }\end{array}$ \\
\hline As habilidades & $\begin{array}{l}\text { Equilibrar técnica, expressão artística, utilidade, para criar uma } \\
\text { atmosfera na qual se pode viver e trabalhar. }\end{array}$ \\
\hline A ideologia arquitetônica & $\begin{array}{l}\text { Desenvolver um repertório e senso crítico sobre arquitetura, suas } \\
\text { funções e suas diversas formas de expressão e estilo. }\end{array}$ \\
\hline
\end{tabular}

Fonte: baseado em Guardavilla (2016). 
Figura 2 - Projeto como resultado de um fazer genial e obscuro, e o projeto como processo transparente, realizado em etapas

Fonte: Sarmento e Gomes (2019, p. 154).
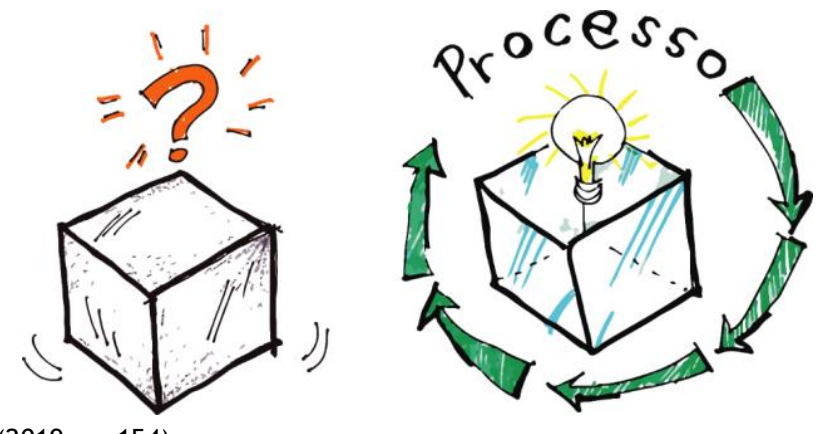

Nos dias atuais, desde a criação de sistemas computacionais, a ferramenta digital de projeto auxiliado por computador tornou o processo de projetar mais complexo, entretanto mais rico e passível de ajustes, sem necessidade de redesenhar elementos por instrumentos manuais, com a inserção da ferramenta computeraided design (CAD), que tornou o desenvolvimento do projeto uma atividade digital. A ferramenta buildinginformationmodeling (BIM) trouxe uma inovação ao reunir "[...] um conjunto de políticas, processos e tecnologias que, combinados, resultam em uma metodologia para gerenciar o processo de projetar de uma edificação, testar seu desempenho, e gerenciar as suas informações utilizando plataformas digitais [...]" (CÂMARA..., 2016). Manzione (2013) complementa que o BIM se caracteriza como "um processo que permite a gestão da informação", e segundo Olegário (2018) é uma ferramenta que integra todos os tipos de projetos, havendo a necessidade de um coordenador, com a função de direcionar e relacionar o trabalho de todos os projetistas envolvidos.

Mesmo considerando todo o avanço tecnológico empregado no desenvolvimento do processo de projetar em arquitetura, a questão do distanciamento entre projetistas e usuários ainda persiste, já que boa parte das edificações de uso coletivo, ou público, é encomendada a arquitetos e designers por gestores e clientes institucionais, que não são os usuários finais. A arquitetura pública de escolas, hospitais, shoppings e aeroportos, por exemplo, são projetadas por profissionais que tem pouco contato com os usuários de suas edificações (LAWSON, 2011). A exemplo disso, Kowaltoskiet al. (2013) pesquisaram os processos de projeto de edificações escolares realizados pela FDE no Brasil e entrevistaram 44 arquitetos. O estudo concluiu que nos processos de projetos escolares raramente são utilizadas informações recentes advindas da literatura especializada. O espaço da sala de aula (espaço principal da atividade escolar) não foi mencionado como objeto de atenção especial durante o processo de projeto (em menos de $5 \%$ dos entrevistados). Os critérios de projeto mais destacados pelos arquitetos foram: iluminação natural (40\% dos entrevistados), ventilação natural e assinatura local (30\% dos entrevistados). Outros requisitos projetuais foram mencionados em menor proporção. Formas e técnicas de ouvir as necessidades dos usuários finais não foram mencionadas.

\section{Contextos da projetação ergonômica}

A ergonomia defende que sejam aprofundados os estudos sobre as especificidades dos espaços, considerando a atividade-fim de cada ambiente e incorporem-se formas de tornar o usuário parte do processo de projetar. As interações sociais entre os usuários fazem parte de um conjunto de significados culturais e sociais que devem ser considerados no fazer projetual, já que a arquitetura proporciona a materialização do conceito de lugar, conforme definido na introdução deste artigo.

Durante o projeto, os projetistas precisam incorporar as restrições técnicas que delimitam o fazer arquitetônico. Estas são geralmente elementos normativos, ou legislativos, com a função de assegurar que a edificação cumpra, da maneira mais adequada possível, as funções exigidas (LAWSON, 2011). Incorporar as restrições normativas tem sido o foco principal dos profissionais, que assumem a responsabilidade técnica projetual diante dos órgãos reguladores municipais e federais.

Ao falar de ergonomia, as necessidades (físicas e psicológicas) de usuários ascendem ao patamar de restrições primárias, ou prioritárias, com a mesma importância de fatores normativos, climáticos ou econômicos, demonstrando a existência de responsabilidade social, extrapolando assim as questões puramente construtivas. Villarouco (2011) destaca o foco da ergonomia em pensar no atendimento da 
diversidade humana e em suas subjetividades. Defende-se a preocupação em estabelecer um perfeito entendimento das necessidades não apenas físicas do usuário de um determinado espaço, mas também da questão da sua percepção/satisfação. Nesse caso, o edifício passa a ser compreendido como espaço vivencial, sujeito aos valores simbólicos e socioculturais dos usuários.

\section{Projetar para o espaço de atividade}

Espaço de atividades é a delimitação de superfície necessária para que uma pessoa possa desenvolver uma atividade sem interferência, ou restrições provocadas pelo mobiliário, pelos equipamentos ou quaisquer barreiras arquitetônicas (BOUERI FILHO, 2008).

Guardavilla (2016, p. 40) define que o "[...] espaço de atividade é um espaço ocupado por uma atividade, ou agregado a uma atividade, ou sobreposto a uma atividade, deslocado do tempo [...]". Compreender a definição de espaço de atividade envolve definir a previsão de espaço no qual a atividade pode ser realizada segundo uma forma e as dimensões estabelecidas no contexto da organização de todos os locais de atividades, das formas e das dimensões que compreendem toda a edificação. Como exemplo, a definição da zona individual de trabalho em uma sala de aula é composta por uma cadeira, uma mesa, mais o espaço de circulação individual. Aplicar esse conceito em projeto de arquitetura significa compreender como a atividade pode ser realizada, e as dimensões estabelecidas, no contexto da organização de todos os espaços de atividades resultantes do todo arquitetônico. Esse é um princípio fundamental da ergonomia aplicada ao ambiente construído, conforme Boueri Filho (2008) e Hedge e Pazell (2017).

Deve-se desenvolver o leiaute de cada ambiente interno, com base em otimizar as zonas de permanência e de circulação de pessoas, aumentar a segurança na realização das atividades, estabelecer a frequência de uso de equipamentos e as zonas de agrupamento funcional das tarefas, as interações com equipamentos e com o mobiliário, estabelecer critérios de proximidade e acessibilidade plena, e verificar a intensidade fluxo. Como exemplo de um espaço de atividade, a Figura 3 ilustra a figura humana executando a atividade de preparação de refeições.

\section{Figura 3 - Estudo do espaço de atividade para a preparação de refeições}

\section{Coifa}
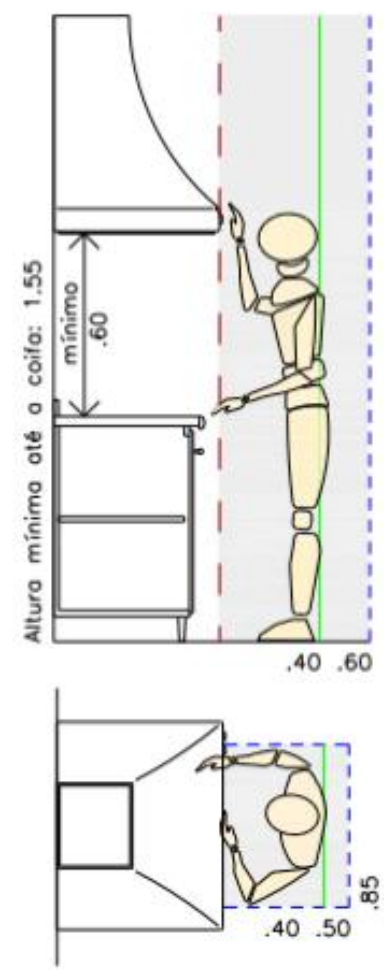

Bancada de Cozinha
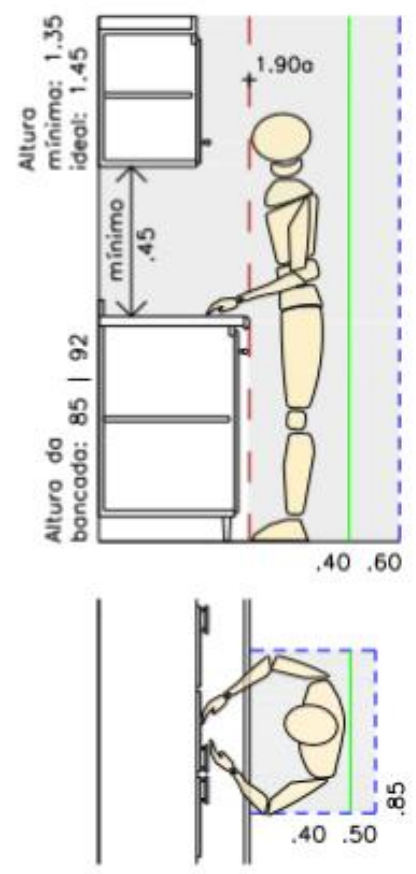

Aplicoçôes Dimensionais

Fonte: Boueri Filho (2008, p. 18).

126 Sarmento, T. S.; Villarouco, V. 
Entretanto, além de conhecer a aplicação dos conceitos do espaço de atividade, a ergonomia esclarece que é fundamental aplicar parâmetros antropométricos de acordo com os tipos e perfis de usuários, considerando a diversidade de tipos e de corpos humanos, diferenças de raça, de gênero, de faixas etárias e de práticas culturais de cada população, em cada região do país.

\section{Projetar com a participação dos usuários}

Incluir os usuários no processo de projeto é uma forma de democratizar o processo decisório de desenvolvimento de um produto ou de uma edificação. Projetos participativos foram iniciados na década de 1970, por Markus (1972) e Cross (1975), e ganharam retomada na era pós-industrial, como forma de maior democratização do processo e incorporação de melhorias advindas de avaliações pós-ocupação, como relatado por Asaro (2000), Sanoff (2001), Muller (2003), Falzon (2007), Gasperini (2010), Pratschke et al. (2005) e Lawson (2011).

Segundo Asaro (2000) e Muller (2003), o design participativo trata o usuário com o mesmo valor dado a um especialista do projeto, participando desde o planejamento até a prototipagem, pois se reconhece seu valor intrínseco, enquanto conhecedor de própria rotina de trabalho ou de vivência em uma determinada situação de projeto. Um dos princípios do design participativo é a motivação de pessoas a envolverem-se no delineamento do futuro produto ou serviço. Isso nos leva à aproximação com os princípios do design science (SIMON, 1996) e do constructive design research (KOSKINEN et al., 2011).

Bühler (2001) destaca que, comumente, os usuários são convidados a participar de processos de design somente quando as etapas principais já foram desenvolvidas, apenas para avaliar ou para intervir em aspectos secundários dos artefatos, ou dos objetos desenvolvidos. Raramente os usuários são convidados a participar de processos de design em estágios iniciais ou de todo o processo de design de um artefato, assumindo um papel fundamental de geração de ideias. Em contrapartida, os usuários frequentemente reclamam de projetos mal elaborados ou ineficientes, que apresentam sérios problemas de inadequação ou más condições de uso. Esse é um cenário que inspira mudanças no sentido de aproximar usuários finais de designers em prol de desenvolver sistemas, projetos e artefatos mais eficientes e próximos das reais necessidades e desejos dos usuários.

O design participativo visa estabelecer uma plataforma interativa de troca de experiências e desenvolvimento de novas ideias, para solucionar problemas e propor soluções mais criativas.

Um projeto desenvolvido com base no design participativo relaciona a interatividade dos usuários com o atendimento de requisitos do projeto e a performance do artefato elaborado, como uma tríade (Figura 4). Isso permite antever erros e inadequações futuras que poderiam não ser percebidos pelos projetistas durante um processo de design convencional.

\section{Bases epistemológicas projetuais}

As bases epistemológicas deste artigo são sedimentadas em estudos da revisão de literatura sobre design, ergonomia do ambiente construído e projeto arquitetônico, especialmente quanto à compreensão de que a produção arquitetônica não deve ser uma atividade meramente tecnicista. Incluir os usuários no fazer projetual pode contribuir para um pensamento holístico, voltado à inclusão social, e proporcionar que a tecnologia seja usada para engajar pessoas sobre o conceito de design science. Desse modo, os subitens a seguir demonstram uma trajetória metodológica que combina o design science research e dois métodos de abordagem ergonômica para o ambiente construído.

\section{Design science research (DSR)}

Design science research é um paradigma epistemológico, de abordagem quantitativa e qualitativa, que concebe um conhecimento sobre como projetar, procura desenvolver e projetar soluções para melhorar sistemas existentes, resolver problemas, ou ainda, criar artefatos (DRESCH et al., 2015). O DSR é aplicado em doze passos metodológicos. De caráter processual, cada um desses passos gera produtos que alimentam os passos seguintes (Figura 5). 
Figura 4 - Fundamentos do design participativo

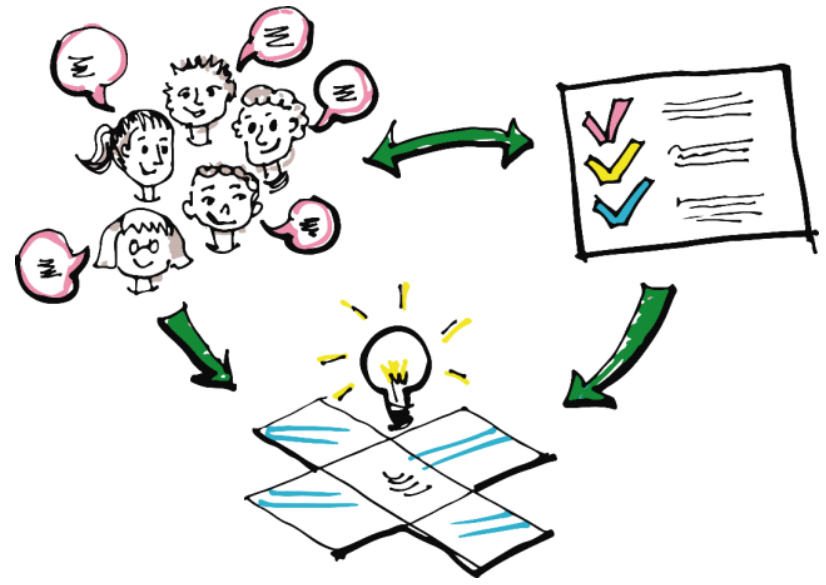

Fonte: Sarmento e Gomes (2019, p.165).

Figura 5 - Sequência metodológica do design science research

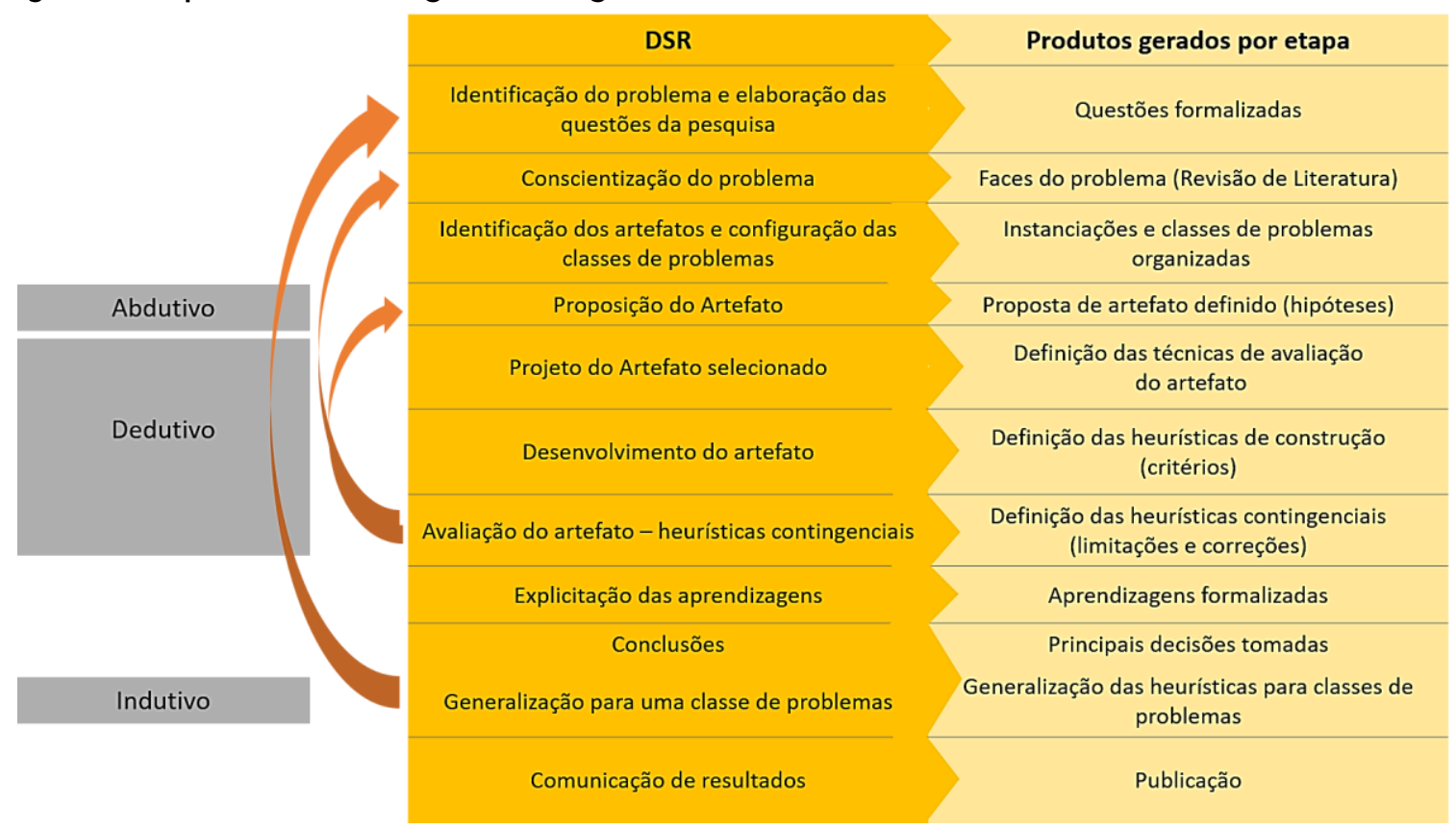

Fonte: adaptado de Dresch, Lacerda e Antunes Junior (2015).

Os passos metodológicos do DSR são:

(a) passo 1: identificação do problema - entender o propósito, a caracterização e o contexto das questões iniciais;

(b) passos 2 e 3: conscientização do problema e revisão de literatura ${ }^{1}$ - imersão no contexto para compreender as relações de causa-efeito sobre o problema, aprofundamento;

(c) passo 4: identificação dos artefatos e configuração das classes de problemas - elaboração de atributos de eficiência para o melhor desempenho das soluções de projeto;

(d) passo 5: proposição de artefatos para resolução do problema - ideação ou proposição de alternativas para as situações analisadas;

(e) passo 6: projeto de artefato - seleção das melhores alternativas, otimização das ideias;

${ }^{1}$ Dresch et al. (2015) recomendam que seja feita uma revisão sistemática de literatura.

128 Sarmento, T. S.; Villarouco, V. 
(f) passo 7: desenvolvimento do artefato - detalhamento das partes ou componentes do projeto;

(g) passo 8: avaliação do artefato - por meio de representação e/ou prototipação, sugere-se a participação de avaliadores experientes e também usuários e de ferramentas digitais de alta fidelidade para reproduzir os elementos do projeto.;

(h) passos 9 e 10: explicitação das aprendizagens e conclusão - tomadas as decisões necessárias e ajustes finais, como nas avaliações anteriores; e

(i) passos 11 e 12: generalização para uma classe de problemas e comunicação dos resultados - por meio do projeto, de relatórios e/ou da execução das ideias.

\section{Ergonomia do Ambiente Construído (EAC)}

A ergonomia do ambiente construído preocupa-se em compreender as necessidades e os desejos dos usuários, a fim de desenvolver soluções para os projetos que possam atender às necessidades físicas e dimensionais, associadas à adoção de estratégias de conforto ambiental, compreensão das necessidades emocionais e psicológicas dos usuários em relação ao espaço construído. Segue o princípio fundamental da ergonomia que coloca o humano como elemento central e primordial de seu pensamento e ações.

Para elaborar uma forma de projetar que possa estar alinhada com as necessidades ergonômicas dos indivíduos e dos ambientes foram combinados dois métodos ergonômicos, um analítico e o outro projetual:

\section{Metodologia ergonômica para o ambiente construído (MEAC) (VILLAROUCO, 2011)}

Propõe um link importante entre ergonomia e arquitetura, que se insere sutilmente entre o cognitivo e o tecnológico, incluindo as questões que tratam das sensações e percepções experimentadas na apropriação espacial pelo usuário. Nessa perspectiva, a MEAC (Quadro 3) consiste em uma avaliação ergonômica que busca identificar conflitos ocasionados por elementos inadequados no ambiente, a partir das opiniões e sugestões dos próprios usuários, aliadas à avaliação técnica do ergonomista que desenvolve o trabalho.

A MEAC adota as ferramentas necessárias à avaliação do espaço com foco nas atividades nele realizadas, verificando possíveis interações prejudiciais ao seu desempenho, bem como as que promovam melhorias das condições de trabalho e de vida. Sua avaliação independe de índices pré-estabelecidos em normativas. Estas são consideradas como balizadores de índices mínimos de conforto, tanto para conforto lumínico, acústico e térmico, quanto para as questões de acessibilidade e segurança. Nessa ótica, o sentimento percebido pelo usuário, somado a sua bagagem cognitiva, emocional e racional, determina os resultados da avaliação.

Dessa forma, obriga-se o pesquisador a utilizar de ferramentas de percepção e psicologia ambiental, em qualquer ambiente que se queira avaliar quando da utilização da MEAC. Sua aplicação é feita em quatro grandes etapas: análise global do ambiente, identificação da configuração ambiental, avaliação do ambiente em uso e análise da percepção do usuário. Ao final são elaborados o diagnóstico ergonômico e as proposições ergonômicas para o ambiente, a partir das interações e análises de todos os elementos coletados.

\section{Projetação ergonômica de Attaianese e Duca (2012)}

Aplicação de princípios ergonômicos em design de edificações, enquanto uma metodologia baseada na aplicação da ISO 9241 (INTERNATIONAL..., 2011) (Quadro 4), que considera que o design envolve a experiência dos usuários, os impactos organizacionais, a reunião de bases documentais dos usuários, pontos fortes, limitações, preferências e expectativas, de acordo com as atividades demandadas e realizadas pelos usuários. Um projeto de edificação centrado no ser humano deveria ser caracterizado por um passo a passo cíclico, relacionando a interatividade dos usuários com os requisitos e performances da edificação. Essa abordagem pode garantir a adequação da edificação às atividades desempenhadas pelos usuários em tempo real.

\section{Resultados e discussões}

A partir da síntese dos métodos projetuais e analíticos apresentados anteriormente, para fins de aplicação projetual, o resultado deste artigo é definir uma sistematização metodológica que possa agregar os conhecimentos teóricos discutidos e descrever etapas projetuais práticas. Dessa forma, a sistematização metodológica é dividida em três etapas principais - observação ergonômica, concepção e desenvolvimento do objeto arquitetônico e avaliação do objeto arquitetônico (subtópicos a seguir) (Figura 6). 
Quadro 3 - Síntese da aplicação da MEAC

\begin{tabular}{|c|c|c|}
\hline \multicolumn{3}{|r|}{ Metodologia ergonômica para o ambiente construído (MEAC) } \\
\hline \multicolumn{2}{|r|}{ Etapas } & Objetivo \\
\hline \multirow{4}{*}{ 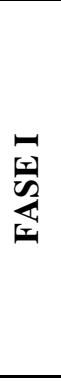 } & $\begin{array}{l}\text { Análise global } \\
\text { do ambiente }\end{array}$ & $\begin{array}{l}\text { Observar informações sobre a estrutura organizacional, a dinâmica da } \\
\text { instituição e os processos de trabalho. }\end{array}$ \\
\hline & \multirow{2}{*}{$\begin{array}{l}\text { Identificação } \\
\text { da } \\
\text { configuração } \\
\text { ambiental }\end{array}$} & Identificar a existência de condicionantes físico-ambientais. \\
\hline & & $\begin{array}{l}\text { Obter informações de ordem física, organizacionais, assim como descrição de } \\
\text { tarefas prescritas. }\end{array}$ \\
\hline & $\begin{array}{l}\text { Avaliação do } \\
\text { ambiente em } \\
\text { uso }\end{array}$ & $\begin{array}{l}\text { Identificar a adequabilidade do ambiente (o quanto ele é facilitador ou } \\
\text { dificultador no desenvolvimento das atividades), analisando os fluxos para a } \\
\text { execução das tarefas. }\end{array}$ \\
\hline \multirow[t]{2}{*}{ 三 } & $\begin{array}{l}\text { Percepção } \\
\text { ambiental }\end{array}$ & $\begin{array}{l}\text { Identificar os desejos dos usuários em relação ao ambiente pesquisado, por } \\
\text { meio de utilização de técnica da psicologia ambiental. }\end{array}$ \\
\hline & \multicolumn{2}{|c|}{ DIAGNÓSTICO | RECOMENDAÇÕES ERGONÔMICAS } \\
\hline
\end{tabular}

Fonte: adaptado de Villarouco (2011).

\section{Quadro 4 - Descrição das etapas de projetação ergonômica}

\begin{tabular}{|c|l|}
\hline Etapa & \multicolumn{1}{c|}{ Descrição } \\
\hline 1 & Design briefing: coleta de dados sobre os objetivos funcionais e o contexto ambiental. \\
\hline 2 & Elaboração dos perfis de usuários e ajuste em grupos. \\
\hline 3 & $\begin{array}{l}\text { Análise de tarefas: identificação dos cenários das tarefas e descrição dos usos dos subcenários } \\
\text { da edificação pelos usuários. }\end{array}$ \\
\hline 4 & Elaboração de requisitos para adaptação às necessidades/expectativas dos usuários e grupos. \\
\hline 5 & Detalhamento arquitetônico e implementação dos requisitos pré-definidos. \\
\hline 6 & Validação das soluções em design. \\
\hline 7 & Monitoramento das performances dos usuários no uso da edificação. \\
\hline
\end{tabular}

Fonte: traduzido de Attaianese e Duca (2012).

Figura 6 - Sistematização do processo de projeto baseado em princípios ergonômicos

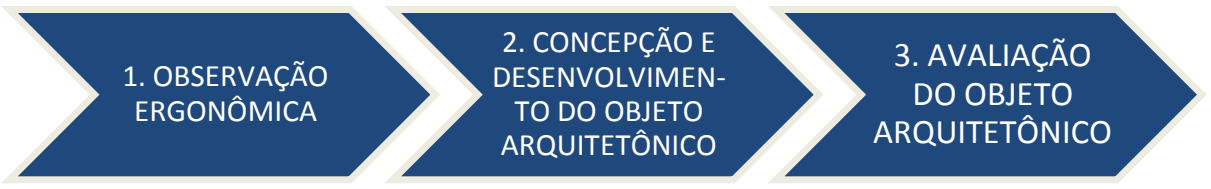

O foco da sistematização do processo de projeto baseado em princípios ergonômicos é de estabelecer uma relação dialógica entre o projetista e $\mathrm{o}(\mathrm{s})$ usuário(s), para troca de informações prévias ao projeto, tangenciando as práticas do design participativo abordados anteriormente.

\section{Observação ergonômica}

A etapa deve ocorrer em ambientes similares pré-existentes, a fim de se realizar a análise do sistema homem - atividade - ambiente, por meio da aplicação de técnicas de observação e análise ergonômicaem subetapas: percepção do projetista, identificação da configuração ambiental, análise do ambiente em uso e análise da tarefa, análise da percepção dos usuários.Considera-se também a busca de avaliações disponíveis na literatura especializada.

Percepção do Projetista - observações e registro da percepção do projetista sobre as situações vivenciadas pelos usuários, seus aspectos positivos e negativos. A aplicação de técnicas de pesquisa etnográfica como ferramenta de coleta de dados permite a participação dos usuários no processo projetual e é bastante usual em design de artefatos (KOSKINEN et al., 2011; FIALHO, 2014; PINK, 2012). Estudo baseados em

130 Sarmento, T. S.; Villarouco, V. 
etnografia têm sido utilizados no campo do design como forma de observar as perspectivas e as práticas realizadas nas situações de estudo, por meio de conversas com as pessoas dentro do seu contexto sociocultural, para explorar, do ponto de vista do indivíduo, sua própria expressão cultural, de acordo com Agrosino (2009), Sanders (2000) e Koskinen et al. (2011). A pesquisa etnográfica, com foco em design, começa com uma investigação cultural, utilizando filmagens, cartas, diários e tarefas aos voluntários, e é enriquecida por registros fotográficos (Figura 7) e anotações sobre o comportamento dos usuários. Os exemplos das Figuras 7 a 10 e Quadros 6 e 8 são genéricos e ilustrativos, podendo ser utilizados ambientes diversos, para explicação das subetapas.

A coleta de dados etnográficos permite que o pesquisador reúna o que as pessoas fazem, o que dizem e como trabalham, por meio de documentos, anotações, fotos, esboços, entre outros (PREECE; ROGERS; SHARP, 2013).

Em seguida, para tornar a imersão um processo de análise consciente por parte dos usuários, aumentando o nível de participação deles nesse processo, realizam-se oficinas ou workshops com os sujeitos, ampliando ou detalhando a compreensão sobre os problemas analisados e a busca por alternativas inovadoras.

A aplicação de ferramentas como o desenvolvimento de personas, brainstorming e a elaboração de cenários, entre outras, permitem aos designers analisar os detalhes dos problemas expostos pelos usuários e, assim, antever a viabilidade de seus conceitos, visando a soluções futuras. Alguns aspectos principais costumam ser considerados para observação em oficinas ou workshops participativos: as pessoas, como acontecem as relações entre elas, o contexto no qual estão, os eventos, as atividades que realizam e os objetos (BLOMBERG et al., 1993; PREECE; ROGERS; SHARP, 2013; GIL, 2008). Esse tipo de pesquisa enfoca a interação dos indivíduos com todos os elementos do contexto (GERHARDT; SILVEIRA, 2009).

Identificação da configuração ambiental - aferição dos condicionantes físico-ambientais que interferem na execução de tarefas, tais como índices de desempenho de conforto térmico, acústico e lumínico, acrescida da análise do leiaute, dos materiais de revestimentos, da existência de legislações e normas específicas para o tipo de ambiente, da acessibilidade física, de fluxos e do dimensionamento dos ambientes similares. Os dados obtidos são organizados em tabelas sintéticas (Quadro 5).

\section{Quadro 5 - Modelo de tabela sintética para análise do ambiente construído}

\begin{tabular}{|c|c|c|c|}
\hline \multicolumn{4}{|l|}{ Nome/Tipo do ambiente } \\
\hline \multicolumn{4}{|l|}{ Área $\left(\mathrm{m}^{2}\right)$} \\
\hline \multicolumn{4}{|l|}{$\begin{array}{l}\text { Croquis dimensionais } \\
\text { previstos/observados }\end{array}$} \\
\hline \multicolumn{4}{|c|}{ Principais atividades previstas/observadas } \\
\hline \multicolumn{4}{|c|}{$\begin{array}{l}\text { Quantidade/Perfis de usuários } \\
\text { previstos/observados }\end{array}$} \\
\hline Fator de desempenho & Índice obtido & Índice recomendado & Observações \\
\hline \multicolumn{4}{|l|}{ Temperatura $\left({ }^{\circ} \mathrm{C}\right)$} \\
\hline \multicolumn{4}{|l|}{ Ruído (Db) } \\
\hline \multicolumn{4}{|l|}{ Iluminação (Lux) } \\
\hline \multicolumn{4}{|l|}{ Natural } \\
\hline \multicolumn{4}{|l|}{ Artificial } \\
\hline Material de acabamento & Cor & Material & Observações \\
\hline \multicolumn{4}{|l|}{ Piso } \\
\hline \multicolumn{4}{|l|}{ Paredes } \\
\hline \multicolumn{4}{|l|}{ Teto } \\
\hline Mobiliário & Cor & Material & Observações \\
\hline \multicolumn{4}{|l|}{ Cadeiras } \\
\hline \multicolumn{4}{|l|}{ Mesas } \\
\hline \multicolumn{4}{|l|}{ Armários } \\
\hline \multicolumn{4}{|l|}{ Porta } \\
\hline \multicolumn{4}{|l|}{ Janelas } \\
\hline \multicolumn{4}{|l|}{ Cortinas } \\
\hline Equipamentos & & & \\
\hline
\end{tabular}


Análise do ambiente em uso e análise da tarefa - monitoramento do posicionamento e da movimentação das pessoas dentro de um espaço, gerando gráficos de fluxo por tipo de atividade, tabelas/quadros sintéticos e/ou mapas de uso. A elaboração de mapas de uso é recomendada por Sanoff (1991) e Sommer, Sommer (1997) para registro de comportamentos no ambiente construído, sendo também recomendanda por Fascioni (2011) como ferramenta de pesquisa etnográfica e por Rheingantz et al. (2009) como ferramenta de percepção da qualidade do lugar.

Para análise das tarefas desenvolvidaspelos usuários, foi elaborado um fluxograma quemostra 3 principais níveis de atividades relativas ao uso do ambiente: o nível 1 trata de atividades de acesso e acomodação no ambiente, o nível 2 refere-se às atividades principais, e o nível 3 refere-se às pequenas atividades de manuseio de instrumentos (Figura 7). Esses dados estão associados a quadros sintéticos (Quadro 6) que detalham as atividades demandadas aos usuários, as condições oferecidas pelo ambiente e a crítica ergonômica dessas condições.

Análise da percepção dos usuários - coleta de dados sobre a percepção dos usuários sobre o ambiente, por meio da aplicação de técnicas de percepção (Figura 8): brainstorming (em grupos focais), constelação de atributos, poema dos desejos (SANOFF, 2001), ou quaisquer outras ferramentas advindas dos estudos da psicologia ambiental. Ao final da etapa, o projetista é capaz de compreender as relações entre usuários e os ambientes que utilizam e como desejam que fossem, se pudessem alterá-los.

\section{Concepção e desenvolvimento do objeto arquitetônico}

Podemos compreender as etapas elementares de um projeto adaptando as teorias de Baxter (2000), Bomfim (1995) e Pazmino (2015) para um projeto de um artefato, seja um objeto, um sistema ou um ambiente. Esses autores afirmam a importância das fases de geração de ideias, seleção das melhores alternativas, assim como da prototipagem, a fim de que protótipos e/ou cenários possam gerar avaliações com usuários e especialistas. Dentro da etapa de concepção e desenvolvimento do objeto arquitetônico apresentam-se as subetapas: design briefing, prototipagem com usuários, síntese dos requisitos ergonômicos e concepção e prototipagem do artefato.

Design briefing - Organização da natureza e justificativa do projeto, conceitos e tendências com base na revisão de literatura e nos dados da análise da percepção dos usuários.

Figura 7 - Níveis de análise ergonômica da tarefa, usando como exemplo um ambiente de aprendizagem

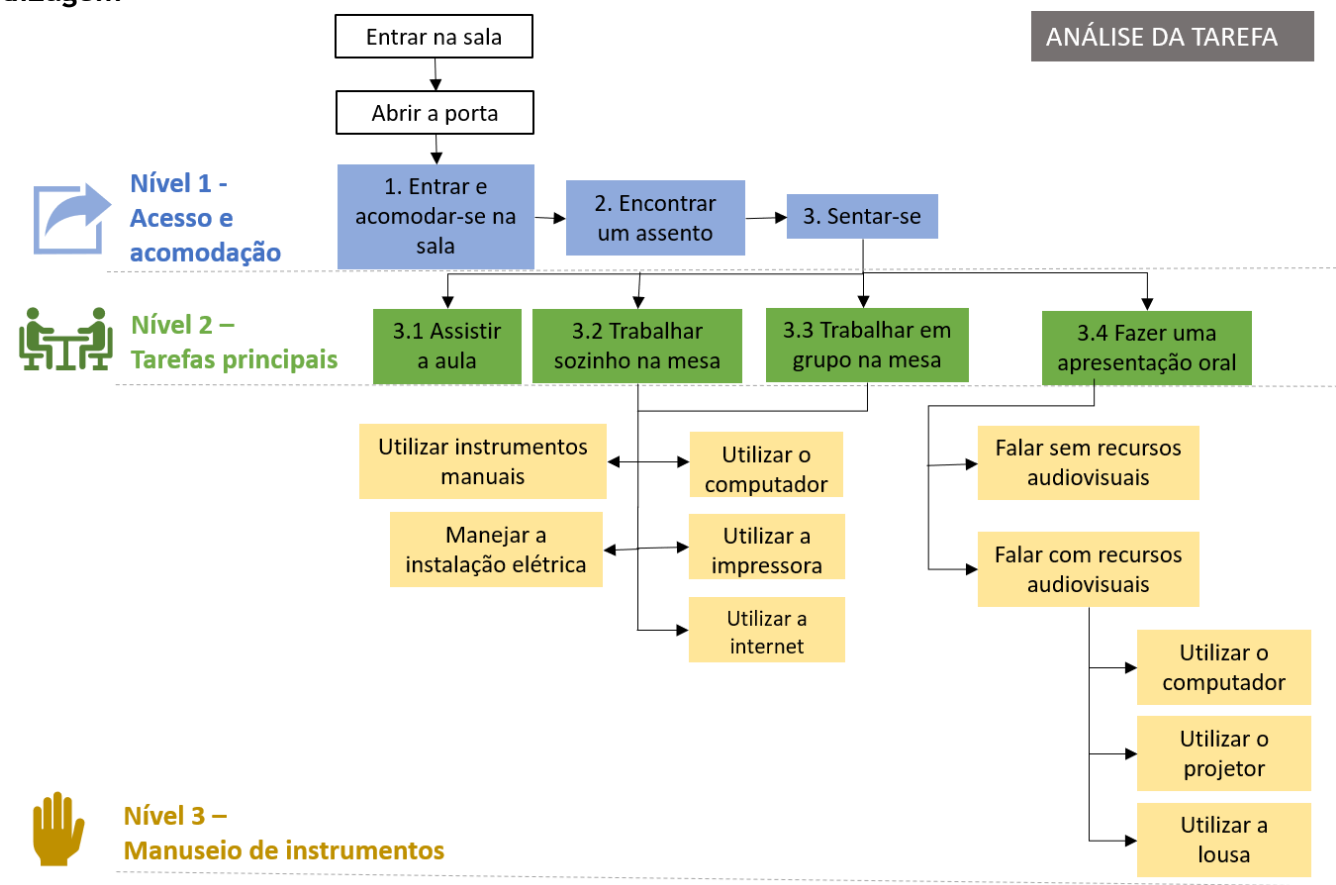

132 Sarmento, T. S.; Villarouco, V. 


\section{Quadro 6 - Sintese da análise do ambiente em uso (restaurante/bar)}

\begin{tabular}{|c|c|c|c|c|c|}
\hline \multirow{2}{*}{\multicolumn{2}{|c|}{ 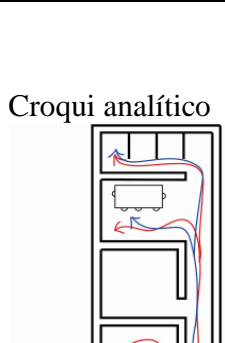 }} & $\begin{array}{l}\text { Atividade observada no } \\
\text { ambiente em uso }\end{array}$ & $\begin{array}{l}\text { Número de } \\
\text { usuários no } \\
\text { momento da } \\
\text { observação }\end{array}$ & $\begin{array}{l}\text { Condição } \\
\text { oferecida pelo } \\
\text { ambiente }\end{array}$ & $\begin{array}{l}\text { Condição recomendada } \\
\text { para o tipo de ambiente }\end{array}$ \\
\hline & & $\begin{array}{l}\text { Acesso e acomodação de } \\
\text { pessoas ao salão principal } \\
\text { (restaurante/bar) }\end{array}$ & 6 & $\begin{array}{l}\text { Portas amplas, } \\
\text { boa iluminação } \\
\text { natural, leiaute } \\
\text { flexível, com } \\
\text { mobiliário leve e } \\
\text { informal }\end{array}$ & $\begin{array}{l}\text { Iluminação mín. } 54 \text { lux } \\
\text { (NR17/NHO11), } \\
\text { circulação livre de } \\
\text { barreiras físicas, com larg. } \\
\text { mín. } 1,00 \mathrm{~m} \text {, piso de } \\
\text { baixo coeficiente de atrito }\end{array}$ \\
\hline \multirow[t]{2}{*}{ 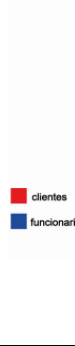 } & \multirow[t]{2}{*}{ 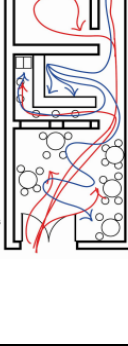 } & Crítica ergonômica & \multicolumn{3}{|c|}{$\begin{array}{l}\text { Por ser uma edificação originalmente residencial, os espaços } \\
\text { internos são pequenos, tanto para os clientes como para os } \\
\text { garçons no trabalho de serviras mesas, especialmente em horários } \\
\text { de pico - almoço, das } 12 \mathrm{~h} \text { às } 13 \mathrm{~h} \text {. Não houve projeto } \\
\text { luminotécnico, ou de interiores, a fim de adequar a edificação ao } \\
\text { novo uso - restaurante. }\end{array}$} \\
\hline & & Recomendação ergonômica & \multicolumn{3}{|c|}{$\begin{array}{l}\text { Recomenda-se utilizar mobiliário mais confortável, permitindo a } \\
\text { permanência dos clientes por mais tempo no restaurante, e usar } \\
\text { iluminação passível de alteração do fluxoluminoso. }\end{array}$} \\
\hline
\end{tabular}

Figura 8 - Síntese dos dados sobre satisfação dos usuários e preferências comportamentais obtidos em (a) estudantes de escolas de ensino médio profissionalizante, e (b) resultado de constelação de atributos aplicada em uma biblioteca universitária

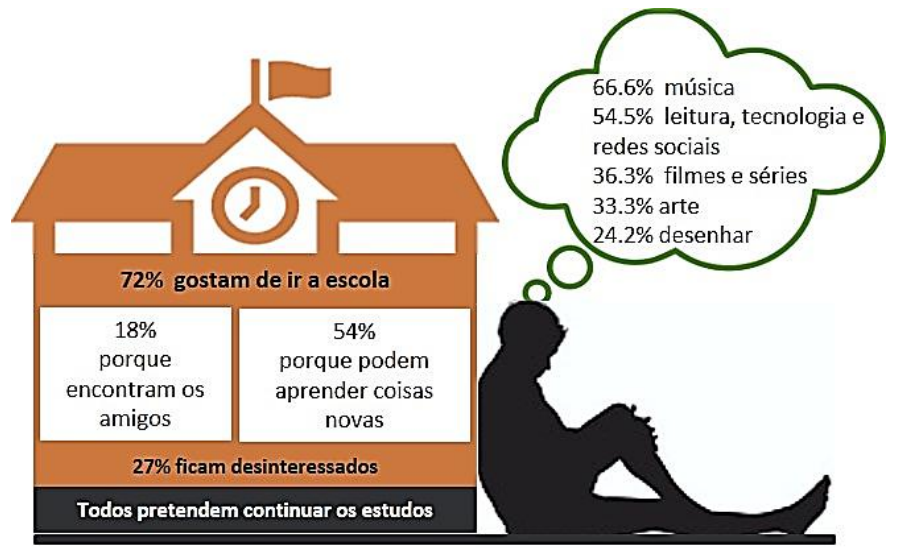

(a)

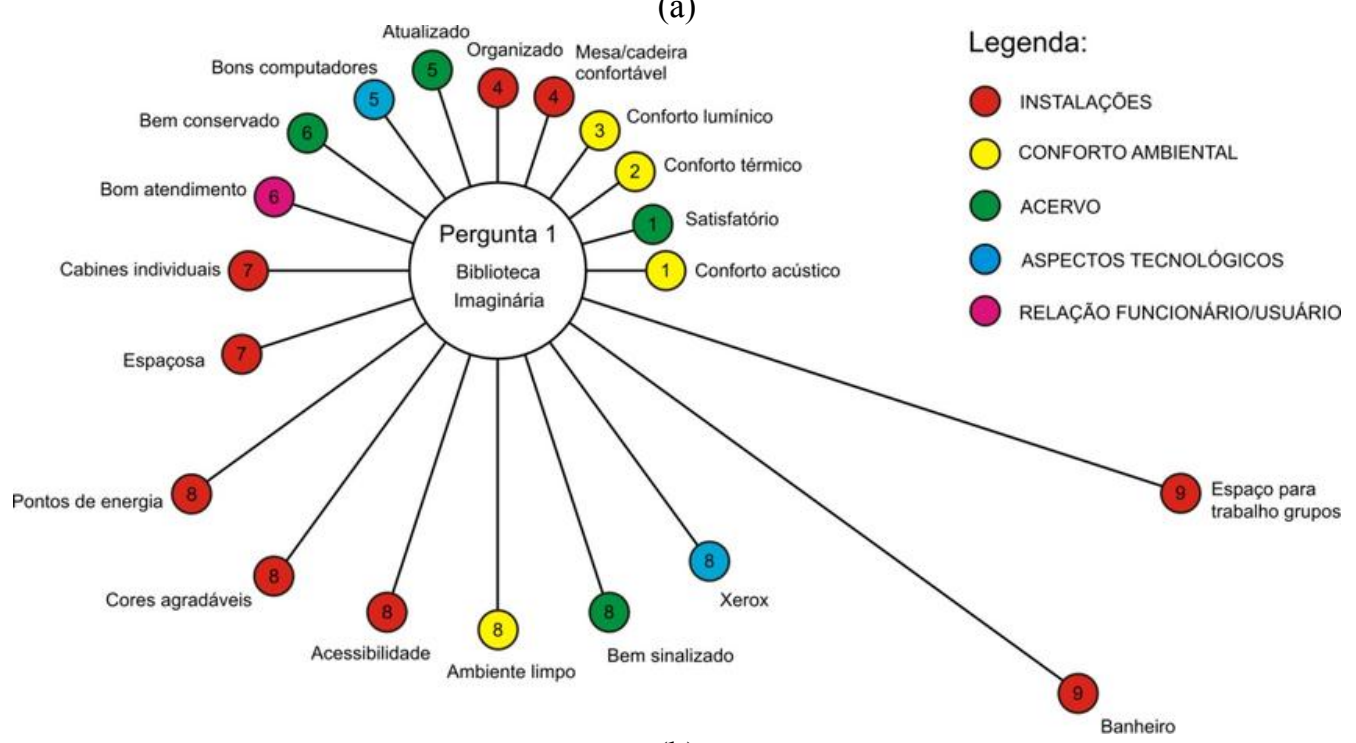

(b)

Fonte: (a) Sarmento (2017) e (b) Falcão, Villarouco e Soares (2009). 
Prototipagem com usuários - Efetiva participação de usuários no desenvolvimento do projeto, por meio da elaboração de cenários das atividades em maquetes físicas, ou protótipos de baixa fidelidade. Projetar com usuários envolve maior interação do projetista com as pessoas que utilizam o espaço. A técnica de oficinas participativas é aplicada em grupos pequenos e médios (entre 15 e 30 pessoas).

O projetista trabalha no papel de mediador, conduzindo a oficina por um período de até uma hora. É importante utilizar ferramentas de fácil compreensão e linguagem, com as quais seja possível aos usuários discutir e elaborar propostas de fácil visualização e representação, seja por meio de desenho ou de modelos físicos. Fialho (2014) afirma que os participantes devem receber um toolkit (ou conjunto) de ferramentas e materiais, que são elementos organizados de forma conveniente para auxiliar os usuários a expressarem seus pensamentos, sentimentos e sonhos, para inspirar e informar à equipe (MARTIN; HANINGTON, 2012). A técnica de prototipagem emmaquete física permite a representação espacial de situações cotidianas, utilizando bonecos e componentes do espaço para dar vida a uma situação ou cenário (Figura 9c), demonstrando desejos e necessidades baseados em suas vivências reais. É uma técnica bastante fácil de conduzir e eficiente na obtenção da interação desejada com os usuários.

Síntese de requisitos ambientais e ergonômicos - Conjunto de diretrizes baseadas nos dados que evoluíram com o processo projetual, descrevendo os detalhes para condições específicas do ambiente e da execução das atividades previstas. As diretrizes ergonômicas podem variar muito, a depender das necessidades dos usuários e do tipo de edificação a ser projetadas, mas recomenda-se trabalhar oito categorias principais (Quadro 7).

Concepção e prototipagem do artefato - Desenvolvimento de desenhos e protótipos, como forma de experimentar ideias, identificar problemas e prevenir erros e comunicar o projeto (SANDERS, 2013; SANDERS; STAPPERS, 2014). Elaboração da edificação em si, e de seus detalhes. Iniciou-se pela elaboração das diretrizes ergonômicas e dimensionais, de acordo com as atividades e o número de usuários, elaboração de croquis de ideias, evoluindo para desenhos de melhor acabamento (Figura 10). O projeto estará concluído quando as representações bi e tridimensionais estiverem em ponto de realizar avaliações com usuários e especialistas.

As representações do projeto podem combinar elementos visuais e áudio-descritivos, simulando a execução das tarefas nos ambientes, além de utilizar realidade virtual, antecipando avaliações que somente seriam possíveis após a construção das edificações.

\section{Avaliação do objeto arquitetônico}

Para avaliação de um projeto em realidade virtual, o projetista deve se preocupar em detalhar os elementos, ou as partes do projeto, uma vez que a percepção do avaliador sobre o objeto pode virar a depender de diversos fatores, seja do pesquisador, do local onde se realiza a sessão de avaliação e até mesmo da qualidade da representação do objeto. Dentro da etapa de avaliação do objeto arquitetônico apresentam-se as subetapas: avaliação com usuários e avaliação com especialistas.

Avaliação com usuários - pode ocorrer individualmente, ou em grupos focais, e proporciona a discussão de aspectos qualitativos percebidos, sendo realizadas em grupos pequenos, de até 8 indivíduos.

Avaliação com especialistas - pode ocorrer individualmente ou em grupos focais, de caráter quantitativo sobre aspectos técnicos do objeto arquitetônico produzido, e constitui restrições importantes ao projeto.

Figura 9 - Etapas de prototipação com usuários para um projeto de intervenção em escolas

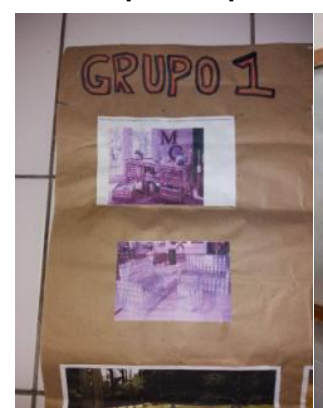

(a) Elaboração de ideias

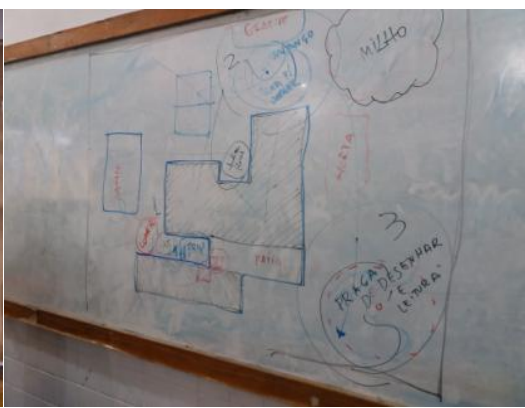

(b) Discussão coletiva

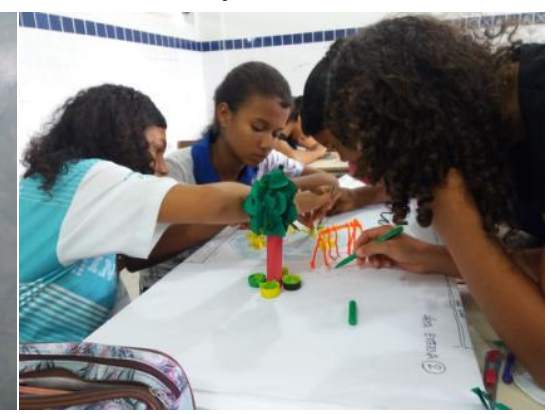

(c) Protogipagem em maquete física

134 Sarmento, T. S.; Villarouco, V. 
Quadro 7 - Categorias principais para elaboração de requisitos ambientais e ergonômicos

\begin{tabular}{|c|c|c|c|}
\hline \multicolumn{4}{|c|}{ TIPO DE EDIFICAÇÃO } \\
\hline EDUCACIONAL & SAÚDE & HABITACIONAL & $\begin{array}{l}\text { COMERCIAL/ } \\
\text { SERVIÇOS }\end{array}$ \\
\hline CATEGORIAS & $\begin{array}{c}\text { REFERÊNCIAS } \\
\text { TÉCNICAS/ } \\
\text { BIBLIOGRÁFICAS }\end{array}$ & $\begin{array}{c}\text { REFERÊNCIA } \\
\text { COM USUÁRIOS }\end{array}$ & DESCRIÇÃO \\
\hline \multicolumn{4}{|l|}{$\begin{array}{l}\text { Condições } \\
\text { construtivas } \\
\text { (materiais e } \\
\text { técnicas) }\end{array}$} \\
\hline \multicolumn{4}{|l|}{$\begin{array}{l}\text { Condições de } \\
\text { conforto } \\
\text { ambiental } \\
\text { (térmico, } \\
\text { lumínico e } \\
\text { acústico) }\end{array}$} \\
\hline \multicolumn{4}{|l|}{$\begin{array}{l}\text { Acessibilidade e } \\
\text { circulação }\end{array}$} \\
\hline \multicolumn{4}{|l|}{$\begin{array}{l}\text { Leiaute, } \\
\text { dimensionamento } \\
\text { e acomodação }\end{array}$} \\
\hline \multicolumn{4}{|l|}{$\begin{array}{l}\text { Mobiliário } \\
\text { (quantidade e } \\
\text { tipos) }\end{array}$} \\
\hline \multicolumn{4}{|l|}{$\begin{array}{l}\text { Instalações } \\
\text { prediais e de } \\
\text { tecnologia }\end{array}$} \\
\hline \multicolumn{4}{|l|}{$\begin{array}{l}\text { Cores e } \\
\text { revestimentos } \\
\text { (externos e } \\
\text { internos) }\end{array}$} \\
\hline Esquadrias & & & \\
\hline
\end{tabular}


Figura 10 - Desenvolvimento de um projeto de ambiente escolar, em suas diferentes fases (a) croqui de ideias principais, (b) leiaute finalizado para avaliação, (c) representação renderizada em 3D; (d) representação em cenário imersivo, para avaliação, (e) detalhamento de mobiliário e (f) leiaute modificado após contribuições das avaliações

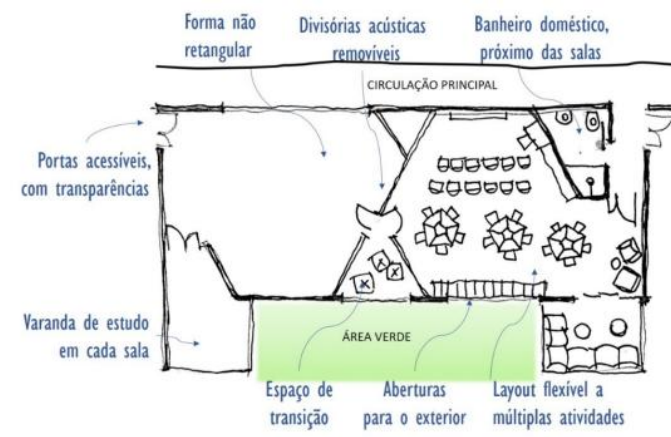

(a) Croqui de ideias principais

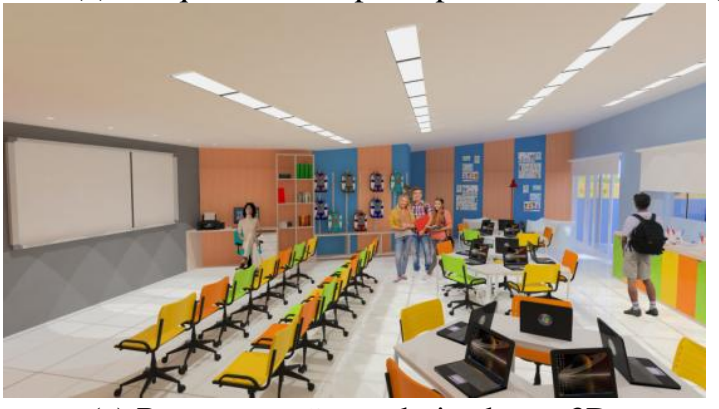

(c) Representação renderizada em 3D

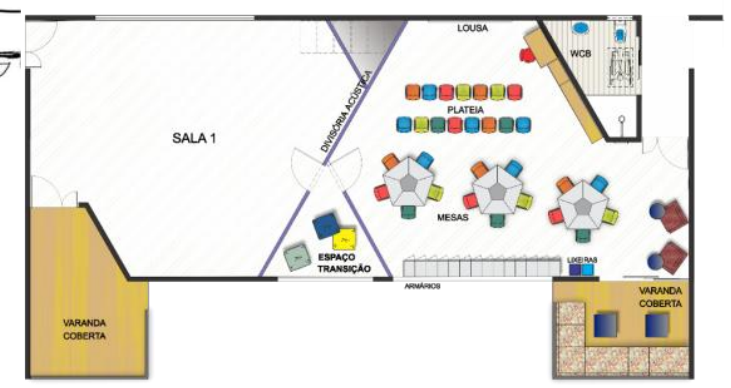

(b) Leiaute finalizado para avaliação

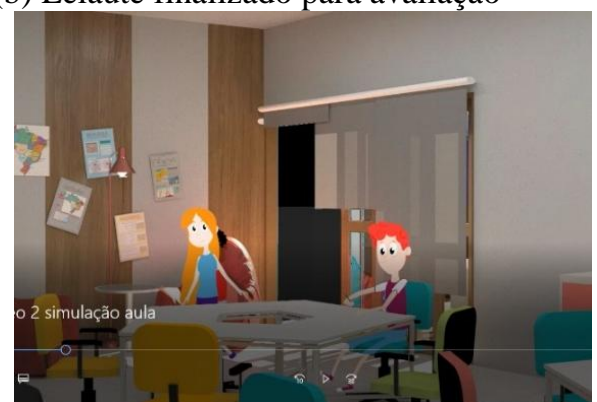

(d) Representação em cenário imersivo

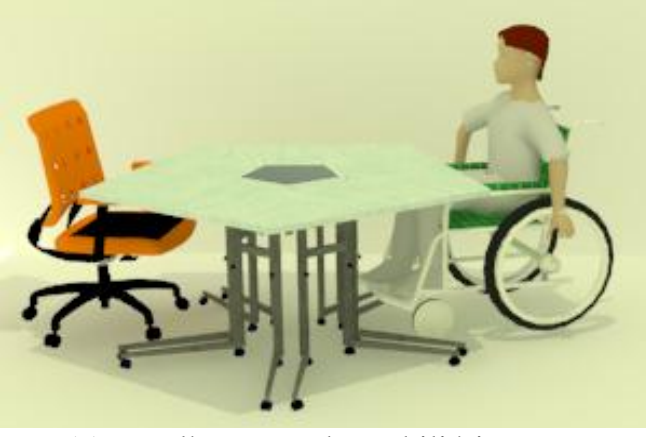

(e) Detalhamento de mobiliário

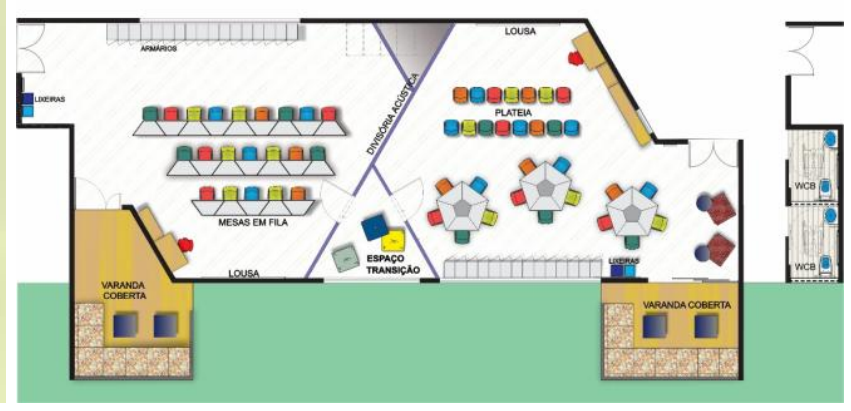

(f) Leiaute modificado após contribuições das avaliações

Fonte: Sarmento (2017).

Para fins de coleta de dados é fundamental aplicar um instrumento de coleta de dados, no formato de entrevista semiestruturada ou questionário, nos quais os avaliadores podem responder às questões pertinentes ao projeto. Os resultados de ambas as avaliações podem ser sintetizados em quadros e/ou gráficos (Quadro 8).

\section{Outras etapas complementares}

Sugere-se o acréscimo de etapas de avaliação do uso e gerenciamento do objeto arquitetônico real, para o caso de a edificação ser construída. Recomenda-se reaplicar a MEAC (VILLAROUCO, 2011; VILLAROUCO et al., 2016) ou análise pós-ocupação (ORNSTEIN, 2017), a fim de verificar se as especificações realizadas em projeto foram realmente eficientes. 
Quadro 8 - Síntese das contribuições obtidas com as avaliações com usuários e especialistas

\begin{tabular}{|l|l|l|}
\hline \multicolumn{1}{|c|}{ Origem } & \multicolumn{1}{|c|}{ Descrição do item } & \multicolumn{1}{c|}{ Alteração realizada } \\
\hline $\begin{array}{l}\text { Usuário } \\
\text { tipo } 01\end{array}$ & Cores muito vibrantes & $\begin{array}{l}\text { Foram ajustadas para tons menos vibrantes, mantendo a } \\
\text { variação de verde, amarelo e laranja em superfícies de paredes, } \\
\text { poltronas, portas dos armários e cadeiras giratórias. }\end{array}$ \\
\hline $\begin{array}{l}\text { Especialista } \\
\text { tipo 01 }\end{array}$ & $\begin{array}{l}\text { Verificar a largura e a } \\
\text { acessibilidade da } \\
\text { porta principal e da } \\
\text { porta para o espaço de } \\
\text { transição }\end{array}$ & $\begin{array}{l}\text { As portas principais foram aumentadas para 1,66 m em duas } \\
\text { folhas, com 0,80 m cada folha, acionamento em giro completo. } \\
\text { Foram verificadas as condições de acessibilidade de acordo com } \\
\text { as recomendações da NBR 9050 (ABNT, 2015) (Figura 74). }\end{array}$ \\
\hline
\end{tabular}

Fonte: Sarmento (2017).

\section{Considerações finais}

A triangulação entre o DSR e os métodos de avaliação e de projetação ergonômicos para o ambiente construído trazem maior profundidade aos temas projetuais, possibilitando obter-se ao longo da pesquisa aprendizagens sobre: o estado da arte sobre o tema projetual, visando a atualização tecnológica e ergonômica das edificações; o despertar da percepção dos usuários sobre os ambientes e edificações que vivenciam, e de que forma realizam suas atividades; a participação de usuários e de especialistas em pensar e em propor, junto com o projetista, soluções inovadoras para os problemas de inadequação ergonômica.

O caráter holístico e a natureza qualitativa das abordagens metodológicas complementaram-se e abriram caminho para a construção de um método inovador, e aprofundado, de como tratar um objeto construído. No campo científico da ergonomia do ambiente construído, essa estratégia representa um ganho importante, poisa sistematização realizada engloba métodos e técnicas de análise e de proposição de acordo com parâmetros ergonômicos.

Os resultados da elaboração dessa sistematização metodológica apontaram para lacunas da participação dos usuários em processos projetuais convencionais. Apresentaram-se as estratégias fundamentais para pesquisadores e projetistas aplicarem a sistematização em seus projetos. Acredita-se na necessidade de novos estudos, mais aprofundados, sobre a inclusão de requisitos ergonômicos, em processos projetuais. Essa é uma habilidade projetual pouco dominada por projetistas em todo o país.

Esta pesquisa permitiu desenvolver a sistematização de etapas prescritivas de princípios de ergonomia ao projeto do ambiente construído. Seu potencial possibilita que haja aperfeiçoamentos futuros, e aplicações em outros estudos sobre diferentes tipologias construtivas.

\section{Referências}

ALEXANDER, C. The state of the art in design methods. DMG Newsletter, v. 5, n. 3, p. 3-7, 1971.

ANDERSON, J. Architectural Design. Basics architecture. Lausanne: AVA Publishing, 2011.

ANGROSINO, M. Etnografia e observação participante. Porto Alegre: Artmed, 2009. (Coleção Pesquisa Qualitativa).

ASARO, P. Transforming society by transforming technology: the science and politics of participatory design. Accounting, Management and Information Technologies, v. 10, p. 257-290, 2000.

ASSOCIAÇÃO BRASILEIRA DE NORMAS TÉCNICAS. NBR 9050: acessibilidadeaedificações, mobiliário e equipamentosurbanos. Rio de Janeiro, 2015.

ATTAIANESE, E.; DUCA, G. Human factors and ergonomic principles in building design for life and work activities: an applied methodology. Theoretical Issues in Ergonomics Science, v. 13, n. 2, p. 187-202, mar./apr. 2012.

BAXTER, M. Projeto de produto, Guia prático para o design de novos produtos. São Paulo: Edgard Blücher, 2000.

BLAKSTAD, S. H.; HANSEN, G. K.; KNUDSEN, W. Methods and tools for evaluation of usability in buildings. Usability of workplaces - part 2. Rotterdam: SINTEF/NTNU, 2008. 
BLOMBERG, J. et al. Ethnographic Field Methods and Their relation to Design.In: SCHULER, D.; NAMIOKA, A. (ed.). Participatory design: principles and practices.Hillsdale: Lawrence Erlbaum Associates, 1993.

BOMFIM, G. A. Metodologia para desenvolvimento de projetos. João Pessoa: Editora Universitária, 1995.

BONNES, M.; SECCHIAROLI, G. Environmental Psychology.London: Sage, 1995.

BOUERI FILHO, J. J. Projeto e dimensionamento dos espaços da habitação, espaços de atividades. São Paulo: Estação das Letras e Cores, 2008.

BÜHLER, C. Empowered participation of users with disabilities in R\&D projects. International Journal of Human-Computer Studies, v. 55, p. 645-659, 2001.

CÂMARA BRASILEIRA DA INDÚSTRIA DA CONSTRUÇÃO. Implantação do BIM para construtoras e incorporadoras: parte 1: fundamentos do BIM. Brasília: CBIC, 2016.

CANTER, D. (org.). Facet theory. Nova York: Springer, 1985.

CANTER, D. The psychology of place.Londres: Architectural Press, 1977.

CANTER, D.; CRAIK, K. H. Environmental Psychology. Journal of Environmental Psychology, p. 1-11, 1981.

CASTELlO, L. Repensando o lugar no Projeto Urbano: variações na percepção de lugar na virada do milênio (1985-2004). Porto Alegre, 2005. Tese (Doutorado em Arquitetura e Urbanismo) - Escola de Arquitetura, Universidade Federal do Rio Grande do Sul, Porto Alegre, 2005.

CROSS, N. Design and technology. Milton Keynes, Open University Press, 1975.

DRESCH, A.; LACERDA, D. P.; ANTUNES JUNIOR, J. A. V. Design science research: método de pesquisa para avanço da ciência e tecnologia. Porto Alegre: Bookman, 2015.

FALCÃO, C. S.; SOARES, M. M. Ergonomia e análise multidisciplinar do ambiente construído. In: ENCONTRO NACIONAL DE ERGONOMIA DO AMBIENTE CONSTRUÍDO, 3., João Pessoa, 2011. Anais [...] João Pessoas: UFPB, 2011.

FALCÃO, C.; VILLAROUCO, V.; SOARES, M. Avaliação ergonômica do Ambiente Construído: estudo de caso em uma biblioteca universitária. Ação Ergonômica, v. 4. p. 5-25, 2009.

FALZON, P. Ergonomia. São Paulo: Editora Blucher, 2007.

FASCIONI, L. Métodos de pesquisa etnográfica. 2011. Disponível em: www.faberludens.com.br. Acesso em: 10 jan. 2017.

FIALHO, U. F. C. S. A pesquisa com usuários no processo de design: sugestões a partir de uma abordagem etnográfica.Porto Alegre, 2014. Dissertação (Mestrado em Design) - Escola de Arquitetura, Universidade Federal do Rio Grande do Sul, Porto Alegre, 2014.

GASPERINI, R. Realidade virtual aplicada à ergonomia por meio do design participativo.Baurum 2010. Dissertação (Mestrado em Design) - Faculdade de Arquitetura, Artes e Comunicação, Universidade Estadual Paulista, Bauru, 2010.

GERHARDT, T. E.; SILVEIRA, D. T. Métodos de pesquisa. Porto Alegre: Editora da UFRGS, 2009. (Série Educação à distância).

GIL, A. C. Métodos e Técnicas de Pesquisa Social. 6. ed. São Paulo: Atlas, 2008.

GUARDAVILLA, B. Progettazionearchitettonica: le logicheprogettuali e ipercorsidell'architetturamoderna.2. ed. Milano: HOEPLI, 2016.

HEDGE, A.; PAZELL, S. Ergonomics and wellness in workplaces.In: HEDGE, A. (ed.) Ergonomic workplace design for health, wellness and productivity. Boca Raton: Taylor \& Francis, C. R. C. Press, 2017.

INTERNATIONAL STANDARDS ORGANIZATION.ISO 9241: ergonomics of human system Interaction.Genebra, 2011.

JONES, J. C. Métodos de diseño. Barcelona: Gustavo Gili, 1978.

138 Sarmento, T. S.; Villarouco, V. 
JONES, J. C.; THORNLEY, D. (ed.). Conference on design methods. Oxford: Pergamon, 1963.

JONGE, T. M. de. Modern woonidealen en woonwensen in Nederland.Vuga, 1960.

KOSKINEN, I.et al. Design research through practice, from the lab, field, and showroom. Whaltan: MK Elsevier, 2011.

KOWALTOWSKI, D. C. C. K. et al. Designing the positive public-school environment: a Brazilian perspective. In: ZANNIN, P. H. T. (org.).Noise and ergonomics in the workplace. Hauppauge: Nova Science Publishers, 2013.

KOWALTOWSKI, D. C. C. K. et al. Reflexão sobre metodologias de projeto arquitetônico. Ambiente Construído, Porto Alegre, v. 6, n. 2, p. 7-19, abr./jun. 2006.

LAWSON, B. Como arquitetos e designers pensam. São Paulo: Oficina de Textos, 2011.

LUCKMAN, J. An approach to the management of design. Operational Research Quarterly, v. 18, n. 4, p. 345-358, 1967.

MALARD, M. L. As aparências em arquitetura. Belo Horizonte: Editora UFMG, 2006.

MANZIONE, L. Proposição de uma estrutura conceitual de gestão do processo de projeto colaborativo com o uso do BIM. São Paulo, 2013. Tese (Doutorado em Engenharia) - Escola Politécnica, Universidade de São Paulo, São Paulo, 2013.

MARKUS, T. A. A doughnut model of the environment and its design. Design Participation. London: Academy Editions, 1972.

MARTIN; B.; HANINGTON, B. Universal Methods of Design. New York: Rockport Publishers, 2012.

MERLEU-PONTY, M. Fenomenologia da percepção. Rio de Janeiro: Freitas Bastos, 1971.

MULLER, M. J. Participatory design: the third space in HCI. In: MAHWAY, N. J. Handbook of HCI. New York: Lawrence Erlbaum, 2003.

OLEGÁRIO, W. L. C. Revisão das atividades desempenhadas pelo coordenador de projetos frente a tecnologia BIM. João Pessoa, 2018.Trabalho de Conclusão de Curso (Graduação em Engenharia) Universidade Federal da Paraíba, João Pessoa, 2018.

ORNSTEIN, S. Avaliação Pós-Ocupação (APO) no Brasil, 30 anos: o que há de novo? Revista Projetar, v. 2, n. 2, p. 7-12, 2017.

PAZMINO, A. V. Como se cria, 40 métodos para design de produtos. São Paulo: Blucher, 2015.

PINK, S. Situating everyday life, practices and places. London: SAGE, 2012.

PRATSCHKE, A. et al. Da participação à colaboração estruturando ambientes digitais de conhecimento. In: IBEROAMERICAN CONGRESS OF DIGITAL GRAPHICS, 9., Peru, 2005. Anais [....] Lima: 2005.

PREECE, J.; ROGERS, Y.; SHARP, H. Design de interação: além da interação homem computador. 3 ed. Porto Alegre: Bookman, 2013.

RHEINGANTZ, P. A. et al. Observando a qualidade do lugar: procedimentos para a avaliação pósocupação. Rio de janeiro: Universidade Federal do Rio de Janeiro, 2009.

SANDERS, E. B. N. Generative tools for codesigning. In: SCRIVENER, A. R.; BALL, L. J.; WOODCOCK, A. (eds.). Collaborative design. London: Springer-Verlag, 2000.

SANDERS, E. B. N. Prototyping for the design spaces of the future. In: VALENTINE, L. (ed.) Prototype: design and craft in the 21st Century. Bloomsbury, 2013.

SANDERS, E.; STAPPERS, P. J. Probes, toolkits and prototypes: three approaches to making in codesigning. CoDesign: International Journal of Co-Creation in Design and the Arts, v. 10, n. 1, p. 514, 2014.

SANOFF, H. A visioning process for designing responsive schools. Washington: NationalClearinghouse for Educational Facilities, 2001.

SANOFF, H. Visual research methods in design. New York: Van Nostrand Reinhold, 1991. 
SARMENTO, T. F. C. S. Modelo conceitual de ambiente de aprendizagem adequado a práticas com blendedlearning para escolas de ensino médio. Recife, 2017. Tese (Doutorado em Design) - Centro de Artes e Comunicação, Programa de Pós-Graduação em Design, Universidade Federal de Pernambuco, Recife, 2017.

SARMENTO, T. S.; GOMES, A. S. Design de Ambiente Escolar para aprendizagem criativa. Recife: Pipa Comunicação, 2019. (Coleção Professor Criativo).

SIMON, H. A. The sciences of the artificial. $3^{\text {rd }}$. ed. Cambridge: MIT Press, 1996.

SOMMER, R.; SOMMER, B. A practical guide to behavioral research, tools and techniques. New York: Oxford, 1997.

SOMMER, R. Personal space: the behavioral basis of design. Englewood Cliffs: Prentice-Hall, 1969.

VILLAROUCO, V. An ergonomic look at the work environment.In: INTERNATIONAL ERGONOMICS ASSOCIATION WORLD CONGRESS, 17., Beijing, 2009. Proceedings [...] Beijing, 2009.

VILLAROUCO, V. et al. Anergonomicsfocusonbuiltenvironment for theelderly. In: SOARES, M; REBELO, F. (ed.). Ergonomics in design. Boca Raton: CRC Press, 2016.

VILLAROUCO, V. Tratando de ambientes ergonomicamente adequados: seriam ergoambientes? In: MONT'ALVÃO, C.; VILLAROUCO, V. (org.). Um novo olhar para o projeto: a ergonomia no ambiente construído. Rio de Janeiro: Faperj, 2AB, 2011.

VOORDT, T. J. M. van der; WEGEN, H. B. R. van. Arquitetura sob o olhar do usuário, programa de necessidades, projeto e avaliação de edificações. São Paulo: Oficina de Textos, 2013.

Thaisa Sampaio Sarmento

Faculdade de Arquitetura e Urbanismo | Universidade Federal de Alagoas | Av. Lourival Melo Mota, s/n, Tabuleiro dos Martins | Maceió AL - Brasil | CEP 57072-900 | Tel.: (82) 3214-1283 | E-mail: thaisa.sampaio@fau.ufal.br

\section{Vilma Villarouco}

Programa de Pós-Graduação em Design, Centro de Artes e Comunicação | Universidade Federal de Pernambuco | Av. da Arquitetura, s/n | Recife -PE - Brasil | CEP 50740-550 | Tel.: (81) 2126-8907 | E-mail: vvillarouco@gmail.com

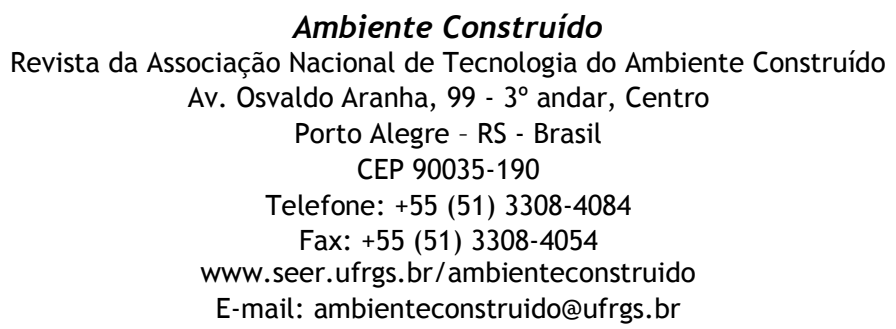

